\title{
Relación entre los indicadores de disponibilidad de fósforo y la respuesta de los cultivos de trigo, maíz y soja a la inoculación con Penicillium bilaii
}

\author{
Silva Rossi, M.M.; A.A. del C. Rollán y O.A. Bachmeier
}

\begin{abstract}
RESUMEN
Se evaluó la relación entre los indicadores de disponibilidad de fósforo y la respuesta de los cultivos de trigo, maíz y soja a la inoculación con Penicillium bilaii. Se trabajó en distintos Molisoles con un diseño en bloques con parcelas completamente aleatorizadas y tres repeticiones para uno de los tratamientos: semillas inoculadas con P. bilaii y testigo sin inocular. Las parcelas de trigo y maíz se fertilizaron con dosis entre 8 y $16 \mathrm{~kg} \mathrm{P} \mathrm{ha}^{-1}$. Para cada tipo de suelo se estimó la energía de retención de fósforo ( $k$ de Langmuir), la capacidad buffer máxima (MBC), el diferencial de capacidad buffer (DCB), el índice de adsorción de fósforo (P-SI) y el índice de disponibilidad fosfórica (F-Index). Se evaluó la respuesta relativa en términos porcentuales del rendimiento máximo $(\mathrm{RR} \%)$ realizando un análisis multivariado de componentes principales y coeficientes de correlación de Pearson. No hubo relación entre la respuesta y la dosis de fertilizante aplicada. La RR\% de los cultivos de trigo y soja se asoció positivamente con los sitios de mayor $k$, mayor MBC y negativamente con FIndex. Para las condiciones de este ensayo, $k$, MBC y DCB se comportaron como indicadores sensibles de la disponibilidad de fósforo.
\end{abstract}

Palabras clave: solubilización de P, absorción, inoculación, respuesta del cultivo.

Silva Rossi, M.M.; A.A. del C. Rollán and O.A. Bachmeier, 2013. Relationship between available phosphorus indicators and wheat, corn and soybean responses to inoculation with Penicillium bilaii. Agriscientia 30 (2): 49-56

\section{SUMMARY}

We assessed the relationship between indicators of phosphorus availability and responses of wheat, corn and soybean to inoculation with Penicillium bilaii. We worked in various Mollisols with block design with completely randomized plots and three replications for each of the treatments: seeds inoculated with P. bilaii and non inoculated control. The wheat and corn plots were fertilized with doses between 8 and $16 \mathrm{~kg} \mathrm{Pha}^{-1}$. For each soil type was estimated the energy of phosphorus retention (Langmuir $k$ ), the maximum buffer capacity (MBC), the differential buffer capacity (DCB), the rate of adsorption of phosphorus (P-SI) 
and phosphate availability index (F-Index). We evaluated the relative response as a percentage of maximum yield (RR\%), performing a principal component and multivariate Pearson correlation coefficients analyses. There was no relationship between response and dose of applied fertilizer. The $R R \%$ of wheat and soybean crops were positively associated with higher $k$ sites, high MBC and negatively with F-Index. For the conditions of this experiment $k, \mathrm{MBC}$ and DCB were sensitive indicators of phosphorus availability.

Key words: dissolution of $\mathrm{P}$, absorption, inoculation, crop response.

M.M. Silva Rossi: Estudio Agronómico, Venado Tuerto, Argentina. A.A. del C. Rollán y O.A. Bachmeier: Facultad de Ciencias Agropecuarias, Universidad Nacional de Córdoba, Av. Valparaíso s/n, C.C. 509, 5000 Córdoba, Argentina. Correspondencia a: obachmei@agro.unc.edu.ar

\section{INTRODUCCIÓN}

Las plantas poseen varios mecanismos para adaptarse a suelos con condiciones de disponibilidad de fósforo limitante. Las propiedades de las plantas que afectan la superficie específica de la raíz, como su longitud y diámetro, pueden afectar en gran medida la tasa de absorción de fósforo. Para aumentar el abastecimiento, las plantas deben tener un sistema radical más fino y largo; así, los microorganismos del suelo pueden promover el crecimiento de las plantas, alterando la morfología de las raíces o influenciando en la cinética de afluencia de nutrientes y agua (Vessey \& Heisinger, 2001).

De los hongos que viven en el suelo, el género Penicillium es conocido por producir numerosas micotoxinas, muchas de las cuales tienen aplicación agrícola (Savard et al., 1994). La especie Penicillium bilaii tiene el potencial para influir considerablemente en la capacidad de absorción de las raíces, lo que resulta en un aumento de la absorción de fósforo e incluso de otros nutrientes, por ejemplo cinc y cobre (Gulden \& Vessey, 2000).

En suelos de Alberta (Canadá) se aisló una cepa de Penicillium bilaii que solubiliza distintas formas de fósforo del suelo y otros micronutrientes. Esta cepa ha sido utilizada como inoculante para incrementar la sanidad, el crecimiento y el rendimiento de varios cultivos (Savard et al., 1994).

$P$. bilaii es un hongo de la rizosfera que incrementa la producción de materia seca, rendimiento en grano y absorción de fósforo en trigo, canola, arveja y lenteja en experimentos de campo e invernadero (Gleddie, 1993).

Los mecanismos por los cuales este hongo estimula el crecimiento de la planta y la absorción de fósforo no se conocen totalmente, pero se ha de- mostrado su capacidad para solubilizar fosfato de calcio en un medio de cultivo agarizado (Kucey, 1983) y con roca fosfórica en un medio de cultivo líquido (Asea et al., 1988). En experimentos en macetas, la inoculación con P. bilaii aumentó la cantidad de fósforo extractable con $\mathrm{NaHCO}_{3}$ (Kucey, 1988). Los principales metabolitos producidos por P. bilaii son los ácidos oxálico y cítrico (Cunningham \& Kuiack, 1992). La evidencia sugiere que este hongo puede aumentar la disponibilidad de fosfato a la planta por la liberación de esos ácidos orgánicos, que pueden actuar para acidificar áreas localizadas de la rizosfera o actuar como un agente quelante de los cationes unidos al fosfato (Kucey, 1988). Sin embargo, la estimulación del crecimiento vegetal por inoculación con $P$. bilaii sin el incremento en el contenido de fósforo en la planta, sugieren la existencia de otros mecanismos para disponer de fósforo en la rizosfera (Downey \& van Kessel, 1990; Keyes, 1990; Chambers, 1992; Gleddie, 1992; Heisinger, 1998). Gulden \& Vessey (2000) demostraron que la inoculación con P. bilaii estimuló la producción de la raíz en cabellera en arveja cultivada en hidroponia. Una estimulación del crecimiento de las raíces y una mayor longitud de la raíz se traduciría en una mayor superficie específica de raíz para acceder al fósforo del suelo.

Estudios realizados por Silva Rossi (2012a) sobre muestras de suelo proveniente de Hapludoles, Argiudoles típicos y Haplustoles énticos de la región central de la Argentina, con tenores de fósforo extractable con Bray \& Kurtz N 1 (P-Bray 1) entre 7 y $29 \mathrm{mg} \mathrm{P} \mathrm{kg}^{-1}$, muestran que este extractante posee baja sensibilidad para cuantificar cambios en la disponibilidad de fósforo por efecto de la historia reciente de fertilización fosfatada (últimos 10 años). Esto se demostró para los cultivos más importantes de la región: trigo, soja y maíz. 
En cambio, otros parámetros como la energía de retención, la capacidad buffer del fósforo del suelo y el tamaño del pool lábil, se comportan en estos suelos como indicadores sensibles a variaciones en la disponibilidad, antes que éstas se expresen en el P extractable con P-Bray 1.

Como hipótesis de trabajo se planteó que la respuesta de los cultivos a la inoculación con P. bilaii se incrementa con la disminución de la disponibilidad de fósforo en el suelo.

A efectos de corroborarla se plantearon los siguientes objetivos: i) cuantificar los parámetros que determinan la disponibilidad de fósforo y ii) evaluar la respuesta de los cultivos a la inoculación con P. bilaii y su relación con la disponibilidad de fósforo en el suelo.

\section{MATERIALES Y MÉTODOS}

El trabajo experimental se llevó a cabo en doce ensayos ubicados sobre cinco tipo de suelos clasificados según la Soil Taxonomy (Soil Survey Staff, 2010) como: Argiudol típico (AT), Argiudol vértico (AV), Argiudol ácuico (AAc), Hapludol típico (HT) y Hapludol tapto nátrico $(\mathrm{HtNa})$. El diseño experimental fue en bloques con parcelas completamente aleatorizadas, con dos tratamientos: testigo y semillas inoculadas con $P$. bilaii y tres repeticiones.

Los cultivos evaluados fueron trigo, soja y maíz. La inoculación se realizó previo a la siembra en tambor horizontal, formulación polvo mojable, marca comercial JumperStart de Novozymes Biologicals Argentina S.A, aplicando en trigo $80 \mathrm{~g}$ cada $1630 \mathrm{~kg}$ de semillas en 10 litros de agua, en soja $80 \mathrm{~g}$ cada $1630 \mathrm{~kg}$ de semillas en 5 litros de agua y en maíz 80 g cada 14 bolsas de 80.000 semillas en 4 litros de agua.

El área bajo estudio abarcó parte de la región centro y noreste de la República Argentina. Los sitios experimentales, se ubicaron en las provincias de Santa Fe (Oliveros), Entre Ríos (Nogoyá, Sosa, Rosario del Tala, Victoria y Urdinarrain), Buenos Aires (Chivilicoy y General Madariaga) y Córdoba (Monte Maíz). En la Tabla 1 se detallan los suelos y cultivos correspondientes a cada sitio.

Los ensayos se ubicaron en lotes de producción, razón por la cual las parcelas de trigo y maíz (ambos tratamientos) recibieron una fertilización fosforada a la siembra. Los lotes estudiados se presentan en detalle en la Tabla 2, indicando su ubicación (localidad) y cantidad de P aplicado, la que responde al manejo nutricional que el productor realiza de cada lote.

Para la caracterización de los sitios, previo a la siembra, se tomaron muestras compuestas de suelo $(\mathrm{mc} \times 25)$ de 0 a $20 \mathrm{~cm}$ de profundidad. En cada una de estas muestras se determinó: la reacción de $\mathrm{pH}$ con electrodo de vidrio en una suspensión agua-suelo 1:1 (v/v), carbono orgánico por el procedimiento de Walkley y Black (Nelson \& Sommers, 1996), fósforo extractable (P-Bray 1) con el método Bray \& Kurtz №1 (Kuo, 1996) y se realizó una evaluación de la disponibilidad de fósforo mediante las siguientes determinaciones.

Capacidad máxima de retención de fosfato

Siguiendo la metodología propuesta por Silva Rossi (2012a), se trazaron isotermas de adsorción poniendo en contacto muestras de los distintos suelos con concentraciones crecientes de $\mathrm{P}$ en solución $(C)$, a fin de estimar la adsorción del nutriente en la fase sólida $(Q)$. Los datos experimentales de las relaciones $Q$ versus $C$ se ajustaron al modelo de isoterma de Langmuir:

$$
Q=\frac{Q_{\max } \times k \times C}{(1+k \times C)}
$$

donde Qmax representa la cantidad máxima de fósforo adsorbido y $k\left(\mathrm{~L} \mathrm{mg}^{-1}\right)$ es un parámetro proporcional a la energía de retención (Sparks, 2003).

Con los parámetros de la isoterma de adsorción se determinó la capacidad buffer máxima (MBC, L $\mathrm{kg}^{-1}$ ) a través de la relación (Silva Rossi, 2012b):

$$
M B C=Q \max \times k
$$

\section{Diferencial de capacidad buffer (DCB)}

La capacidad buffer (CB) de fósforo de un suelo se define como la inversa de la pendiente de la curva del potencial fosfato (Beckett \& White, 1964). Esta expresión es válida para una relación lineal; para relaciones cuadráticas, la $\mathrm{CB}$ depende no sólo del tipo de suelo, sino también del punto de la curva en el cual se mide la pendiente. El valor medido en el punto Qo, cantidad de fósforo adsorbido en la ordenada al origen de potencial fosfato, es diferente al medido en el punto Qi, cantidad de fósforo adsorbido en un punto cualquiera, "i", de la curva. Por ello Jensen (1971) sugiere el uso de diferencial de la capacidad buffer del fósforo del suelo (DCB), el cual mide la cantidad de fósforo que se debe agregar o remover de un suelo para tener una cierta variación en el potencial fosfato. En este trabajo se evaluó el DCB tomando como límites de $Q=0$ y $Q=40$ ( $\mathrm{mg} \mathrm{P} \mathrm{kg}^{-1}$ ), fracción de la isoterma en la cual se influye con las dosis de fósforo normalmente aplicadas en la fertilización 
(entre 8 y $10 \mathrm{~kg} \mathrm{P} \mathrm{ha}^{-1}$ ) y donde mayor diferencia se observa en la energía de retención de fósforo por efecto de la historia de manejo y fertilización de los suelos (Silva Rossi, 2012a).

\section{Índice de adsorción de fósforo (P-SI)}

Bache y Williams (1971) desarrollaron un índice de adsorción de fósforo (P-SI) que permite determinar la capacidad de sorción de fósforo del suelo, estimándola a partir de un único punto de la isoterma de adsorción Langmuir (60 ppm P en solución) trabajando con suelos ácidos y calcáreos de Inglaterra. Dicho punto se correlaciona con la capacidad máxima de adsorción de fósforo, estimada a partir de la elaboración de isotermas de Langmuir. Estudios posteriores confirmaron su utilidad como estimador de capacidad de adsorción (Axt et al., 1999; Indiati \& Sharpley, 1995; Börling et al., 2001; Hansen et al., 2002; McDowell \& Condrom, 2004).

El índice de adsorción de fósforo (P-SI) se calcula mediante la siguiente expresión:

$$
\mathrm{P}-\mathrm{SI}=\frac{X}{(\log C)}
$$

donde $X$ es la cantidad de fósforo adsorbido (mg P kg-1 suelo) y C la concentración de fósforo en la solución en equilibrio (mg P L-1 solución).

En este trabajo se calibró la estimación de Qmax a través del P-SI.

\section{Índice de disponibilidad fosfórica (F-Index)}

Expresa qué proporción del fósforo agregado al suelo se recupera para diferentes cantidades de fósforo disponible (Indiati et al., 1995). Esta proporción limita a "F" a valores entre 0 y 1 , donde 0 expresa una total fijación del fósforo aplicado (formas no disponibles) y valores de 1, 100\% de fósforo extractable (formas disponibles), por lo cual este índice se considera un parámetro de disponibilidad del fósforo agregado (Indiati et al., 1999). Para su determinación se dejaron en estado de equilibrio durante 24 horas dos muestras de $2,5 \mathrm{~g}$ de suelo con $25 \mathrm{~mL}$ de solución de $\mathrm{KCl} 0,02 \mathrm{~N}$, una con 60 $\mathrm{mg} \mathrm{P} \mathrm{L-1}$ y otra sin agregado de $\mathrm{P}$ adicional ( $\mathrm{P}$ solución sin $\mathrm{P}$ ). Al término, se centrifugó y se determinó el tenor de fósforo del sobrenadante. El índice "F" se calculó con la siguiente fórmula (Indiati et al., 1995):

$F=\frac{\left(P \text { en extracto con } 60 \mathrm{mg} P L^{-1}-P \text { solución } \sin P\right)}{\text { P agregado }}$

\section{Rendimiento y análisis de datos}

Debido a la gran variabilidad ambiental en los sitios experimentales, se evaluó la respuesta relativa porcentual del tratamiento inoculado con respecto al testigo. El análisis estadístico de los datos experimentales se realizó mediante regresiones lineales y no lineales, análisis multivariado de componentes principales y coeficientes de correlación de Pearson con el programa Infostat (Di Rienzo et al., 2011).

\section{RESULTADOSY DISCUSIÓN}

En la Tabla 1 se presentan algunas características analíticas de los suelos estudiados y en la Tabla 2 la respuesta relativa de los cultivos empleados a la aplicación de P. bilaii y los índices de disponibilidad de P. La relación entre los valores de Qmax y P-SI se muestra en la Figura 1. En la Figura 2 se ilustran ejemplos de isotermas de adsorción de fósforo para algunos suelos característicos,

Tabla 1. Ubicación y clasificación taxonómica de los suelos, cultivo empleado, $\mathrm{pH}$, carbono orgánico (CO) y P extractable (P-Bray 1).

\begin{tabular}{|c|c|c|c|c|c|}
\hline Localidad & Suelo & Cultivo & $\mathrm{pH}$ & $\mathrm{CO}\left(\mathrm{g} \mathrm{kg}^{-1}\right)$ & P-Bray $1\left(\mathrm{mg} \mathrm{kg}^{-1}\right)$ \\
\hline Chivilicoy & Hapludol típico & Maíz & 5,41 & 19,2 & 11,3 \\
\hline Gral. Madariaga (1) & Hapludol tapto nátrico & Soja & 5,62 & 13,9 & 7,0 \\
\hline Gral. Madariaga (2) & Hapludol tapto nátrico & Soja & 5,70 & 28,1 & 5,2 \\
\hline Monte Maíz & Hapludol típico & Soja & 6,40 & 12,1 & 11,2 \\
\hline Nogoyá (1) & Argiudol vértico & Soja & 6,28 & 18,1 & 20,2 \\
\hline Urdinarrain (1) & Argiudol típico & Soja & 6,31 & 15,0 & 3,4 \\
\hline Urdinarrain (2) & Argiudol ácuico & Soja & 7,76 & 12,1 & 9,0 \\
\hline Nogoyá (2) & Argiudol vértico & Trigo & 6,63 & 15,7 & 23,6 \\
\hline Oliveros & Argiudol típico & Trigo & 6,17 & 19,2 & 8,6 \\
\hline Rosario del Tala & Argiudol vértico & Trigo & 6,11 & 11,6 & 9,9 \\
\hline Sosa & Argiudol ácuico & Trigo & 5,93 & 16,1 & 9,1 \\
\hline Victoria & Argiudol típico & Trigo & 5,86 & 18,8 & 53,9 \\
\hline
\end{tabular}


ajustadas al modelo de Langmuir, cuyos parámetros se detallan en la Tabla 2.

Los sitios experimentales analizados presentaron marcadas diferencias en los parámetros edáficos evaluados. Los mayores contrastes se hallaron entre los Argiudoles con contenidos de P extractable

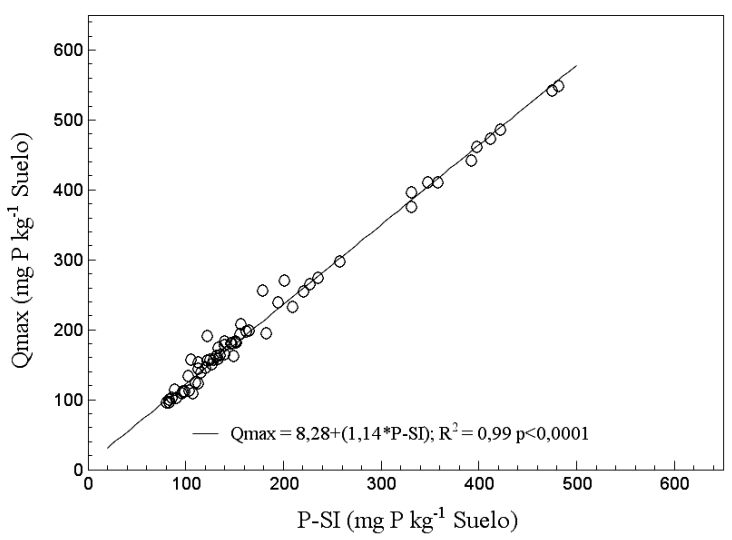

Figura 1. Relación entre la capacidad máxima de adsorción según el modelo de Langmuir (Qmax) y el índice de adsorción de fósforo (P-SI), para muestras de 45 suelos de la región pampeana Argentina, con distintas propiedades físico químicas.
(P-Bray 1) comprendidos entre un mínimo de 3,5 y un máximo de $54 \mathrm{mg} \mathrm{kg}^{-1}$, mientras que en los Hapludoles típicos y los Hapludoles tapto nátricos los contenidos de P-Bray 1 estuvieron comprendidos entre 5 y $11 \mathrm{mg} \mathrm{kg}^{-1}$, respectivamente (Tabla 1).

En relación a los indicadores de disponibilidad

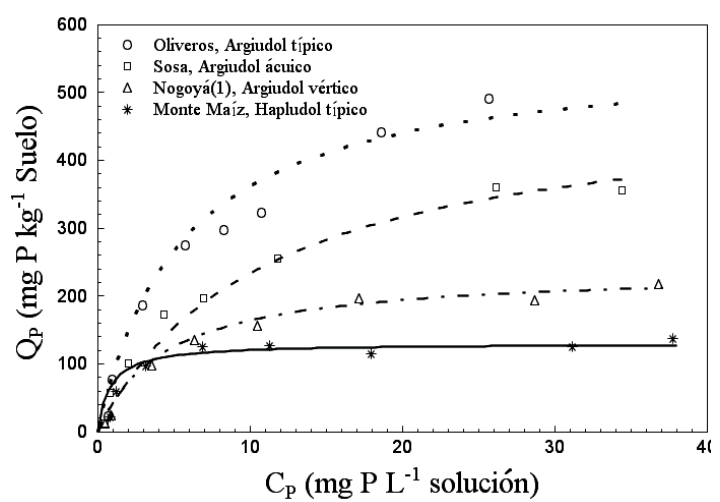

Figura 2. Isotermas de adsorción de fósforo ajustadas al modelo de Langmuir en algunos suelos característicos, seleccionados a modo de ejemplo. Puntos: datos experimentales de $\mathrm{P}$ adsorbido $\left(Q_{p}\right)$ versus concentración en solución en equilibrio $\left(C_{p}\right)$; líneas: ajuste por regresión no linear al modelo de Langmuir.

Tabla 2. Dosis de P, respuesta relativa (RR) a la aplicación de P.bilaii, indicadores de disponibilidad de fosforo: cantidad máxima fósforo adsorbido (Qmax), constante de energía de adsorción (k), índice de adsorción de fósforo (P-SI), capacidad buffer máxima (MBC), diferencial de capacidad buffer (DCB) e índice de disponibilidad fosfórica (F-Index).

\begin{tabular}{|c|c|c|c|c|c|c|c|c|}
\hline Localidad & $\begin{array}{c}P \\
\left(\mathrm{~kg} \mathrm{ha}^{-1}\right)\end{array}$ & $\begin{array}{c}\mathrm{RR} \\
(\%)\end{array}$ & $\underset{\left(\mathrm{mg} \mathrm{kg}^{-1}\right)}{\mathrm{Qmax}}$ & $\begin{array}{c}\mathrm{k} \\
\left(\mathrm{L} \mathrm{mg}^{-1}\right)\end{array}$ & $\begin{array}{c}\mathrm{P}-\mathrm{SI} \\
\left(\mathrm{mg} \mathrm{kg}^{-1}\right)\end{array}$ & $\begin{array}{c}\text { CBM } \\
\left(\mathrm{L} \mathrm{kg}^{-1}\right)\end{array}$ & DCB & F-Index \\
\hline Chivilicoy, HT & 14 & 4,3 & 608 & 0,06 & 346 & 36,5 & 25,1 & 0,28 \\
\hline Gral.Madariaga(1), HtNa & 0 & 0 & 161 & 0,48 & 139 & 77,3 & 58,0 & 0,15 \\
\hline Gral. Madariaga(2), HtNa & 0 & 8,6 & 166 & 0,42 & 138 & 69,7 & 79,9 & 0,11 \\
\hline Monte Maíz, HT & 0 & 8,8 & 128 & 1,24 & 117 & 158,7 & 164,1 & 0,06 \\
\hline Nogoyá(1), AV & 0 & 1,4 & 238 & 0,22 & 195 & 52,4 & 91,0 & 0,10 \\
\hline Urdinarrain(1), AT & 0 & 7,5 & 112 & 0,83 & 89 & 93,0 & 77,5 & 0,11 \\
\hline Urdinarrain(2), Aac & 0 & 20,9 & 251 & 0,50 & 220 & 125,5 & 210,0 & 0,05 \\
\hline Nogoyá(2), AV & 18 & 2,0 & 617 & 0,23 & 480 & 141,9 & 284,0 & 0,03 \\
\hline Oliveros, AT & 8 & 3,9 & 562 & 0,18 & 422 & 101,2 & 298,0 & 0,03 \\
\hline Rosario del Tala, AV & 10 & 3,6 & 529 & 0,42 & 474 & 222,2 & 485,0 & 0,02 \\
\hline Sosa, Aac & 9 & 3,8 & 492 & 0,09 & 332 & 44,3 & 131,0 & 0,07 \\
\hline Victoria, AT & 16 & 2,5 & 458 & 0,22 & 398 & 100,8 & 148,7 & 0,06 \\
\hline
\end{tabular}

Nota: HT: Haplustol típico; HtNa Hapludol tapto nátrico; AV: Argiudol vértico; AT: Argiudol típico; AAc: Argiudol ácuico.

de fósforo, en la Figura 1 se observa que el índice P-SI estima con exactitud y precisión $\left(r^{2}=0,99\right.$ y $\mathrm{p}<0,0001)$ los valores de $\mathrm{Qmax}$ obtenidos a través del ajuste de los datos experimentales al modelo Langmuir, para un rango de 75 a $580 \mathrm{mg} \mathrm{P} \mathrm{kg}^{-1}$ de suelo. De tal manera, el planteo de este tipo de isotermas constituye una determinación sencilla que puede ser utilizada para evaluar esta importante propiedad de los suelos, relacionada con la fertilidad fosfatada.

Las relaciones entre los parámetros de las isotermas de adsorción de Langmuir, las propiedades físico químicas de los suelos y la respuesta del cultivo de trigo y soja a la inoculación con $P$. bilaii se analizaron mediante análisis multivariado de componentes principales, cuyos resultados se obser- 
van en los biplot de las Figuras 3 y 4.

Para el cultivo de trigo (Figura 3), este análisis con los primeros dos componentes (Cp1 y Cp2) explicó el $77,1 \%$ de la variabilidad total observada. Para el cultivo de soja el $79,4 \%$ de la variabilidad total también es explicada con los primeros dos com-

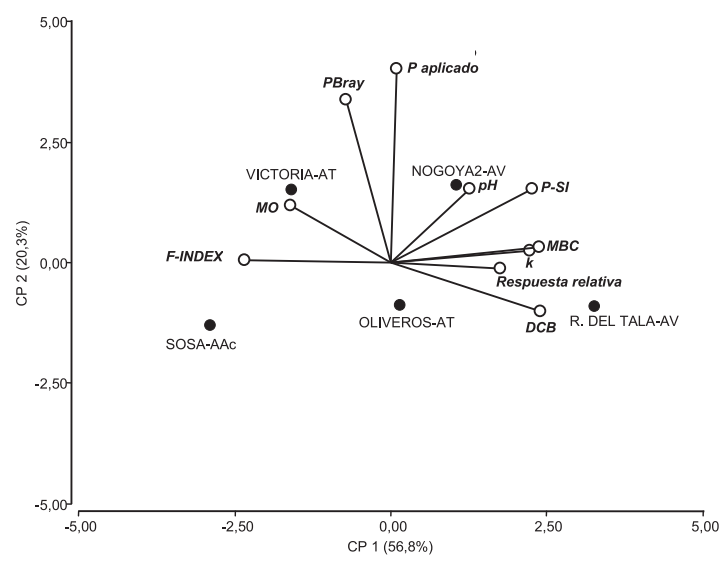

Figura 3. Trigo: Biplot del análisis de componentes principales, para los cinco sitios de ensayo en relación a los tenores de materia orgánica (MO), fósforo extractable con P-Bray 1 (PBray), reacción de $\mathrm{pH}(\mathrm{pH})$, capacidad máxima de adsorción de fósforo (estimada con P-SI), energía de retención de fosfato (k), capacidad buffer máxima (MBC), diferencial de capacidad buffer (DCB), índice de disponibilidad fosfórica (F-INDEX), dosis de P aplicado y respuesta del cultivo a inoculación con Penicillium bilaii.

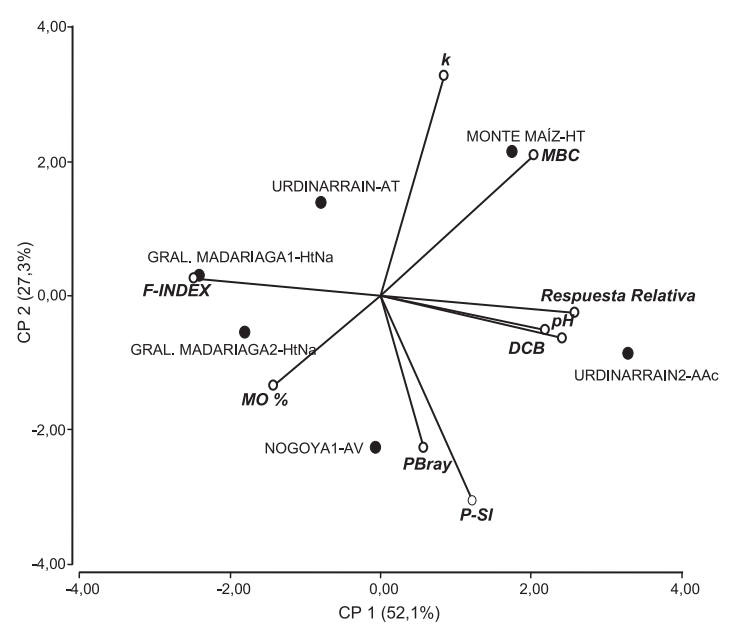

Figura 4. Soja: Biplot del análisis de componentes principales, para los siete sitios de ensayo en relación a los tenores de materia orgánica (MO), fósforo extractable con P-Bray 1 (PBray), reacción de $\mathrm{pH}(\mathrm{pH})$, capacidad máxima de adsorción de fósforo (estimada con P-SI), energía de retención de fosfato (k), capacidad buffer máxima $(\mathrm{MBC})$, diferencial de capacidad buffer $(\mathrm{DCB})$, índice de disponibilidad fosfórica (F-INDEX) y respuesta del cultivo a la inoculación con Penicillium bilaii. ponentes. En ambos cultivos la respuesta en rendimiento se incrementa con el primer componente.

En los biplot los puntos representan los sitios de los ensayos y los vectores las variables medidas; la proyección perpendicular de los puntos sobre los vectores indica la posición relativa de ese sitio para esa variable en particular con respecto a las demás. Mayor será el valor de la variable para un sitio dado cuando se encuentre en el sentido positivo del vector. El ángulo entre los vectores indica el grado de correlación. Así, vectores con ángulos agudos presentarán correlaciones positivas; ángulos rectos, falta de correlación; planos, correlación negativa.

El análisis realizado para ambos cultivos mostró que los sitios experimentales con respuesta a inoculación de las semillas con P. bilaii no se corresponden con los sitios con menores tenores de fósforo extractable con el método Bray \& Kurtz Nº1. Esto coincide con lo observado por Silva Rossi (2012 a), e indica que para las condiciones experimentales evaluadas en este trabajo el método Bray \& Kurtz $\mathrm{N}^{\circ} 1$ no fue sensible como indicador de la disponibilidad de P.

La respuesta del cultivo de trigo a la aplicación de $P$. bilaii se incrementa en el cuadrante derecho del biplot; así mismo, se asocia positivamente con los sitios de mayor energía de retención de fósforo $(k)$ y mayor capacidad buffer máxima (MBC) y negativamente con el índice de disponibilidad fosfórica (F-Index). Esto muestra que la medida o estimación, según corresponda, de los parámetros citados constituye una importante herramienta con fines de diagnóstico y, además, que en condiciones similares a las evaluadas en este estudio, $\mathrm{k}$, MBC y F-index se comportan como indicadores sensibles de la disponibilidad de P.

Para el cultivo de soja se observaron relaciones similares a las encontradas en el cultivo de trigo (Figura 4). La respuesta a la aplicación de esta tecnología fue mayor en los sitios con menor disponibilidad de fósforo, la cual disminuyó en forma relativa con el incremento del primer componente (CP1) y negativamente con el índice de disponibilidad fosfórica (F-Index).

Las relaciones planteadas se corroboraron a través de los correspondientes coeficientes de correlación de Pearson, que se presentan en la Tabla 3. En ella se observa una alta correlación positiva entre los índices que miden una menor disponibilidad de fósforo ( $k, M B C$ y $D C B$ ) y el rendimiento de trigo y soja, y, una correlación negativa cuando mayor es la disponibilidad del nutriente en el suelo (F-index).

En el único sitio donde se evaluó el cultivo de 
Tabla 3. Coeficientes de correlación de Pearson entre respuesta de los cultivos de soja y de trigo y los parámetros de suelo evaluados: índice de adsorción de fósforo P-SI, capacidad buffer máxima (MBC), diferencial de capacidad buffer (DCB) e índice de disponibilidad fosfórica (F-Index). Nivel de significancia: *** $\mathrm{p}<0,001,{ }^{\star *} \mathrm{p}<0,05,{ }^{*} \mathrm{p}<0,10$.

\begin{tabular}{llc}
\hline Parámetro & Soja & Trigo \\
\hline P aplicado & 0,00 & 0,04 \\
pH & $0,93^{\star \star \star}$ & 0,51 \\
Carbono orgánico & $-0,56$ & $-0,65$ \\
P-Bray 1 & 0,20 & $-0,29$ \\
P-SI & 0,55 & $0,92^{\star \star \star}$ \\
k & 0,22 & $0,90^{\star \star *}$ \\
MBC & $0,76^{\star *}$ & $0,96^{\star \star \star}$ \\
DCB & $0,97^{\star \star *}$ & $0,97^{\star \star *}$ \\
F-INDEX & $-0,94^{\star \star *}$ & $-0,95^{\star \star *}$ \\
\hline
\end{tabular}

maíz (Chivilcoy) se encontró una respuesta positiva a la inoculación de las semillas con $P$. bilaii; si bien este suelo presenta una baja energía de retención, lo que contribuye a una mayor disponibilidad de $P$, la respuesta al agregado de este nutriente está asociada con los bajos contenidos de fósforo Bray. Por esta razón, en estas condiciones P-Bray 1 actuó como indicador sensible de la disponibilidad de $\mathrm{P}$, más allá de la baja capacidad del suelo de fijar en compuestos de alta energía $(k=0,06)$ las bajas dosis de fósforo aplicado (14 kg P/ha).

En estas condiciones la respuesta relativa a la inoculación de las semillas de maíz puede deberse ya sea a la producción y liberación de ácidos orgánicos que generaron un medio favorable para la solubilización del P aplicado (Reyes et al., 2002), o bien al desarrollo diferencial del sistema radical (por aumento aparente de la superficie específica), incrementando la eficiencia de absorción de este nutriente (Vessey \& Heisinger, 2001).

La respuesta a la inoculación de los cultivos confirma la hipótesis de trabajo, por la cual este hongo incrementa la asimilación del nutriente por las plantas cuando hay condiciones limitantes para su aporte edáfico. Esto sucede por la acción de uno o la combinación de varios de los mecanismos propuestos por la bibliografía (Downey \& van Kessel, 1990; Keyes, 1990; Chambers, 1992; Gleddie, 1992; Heisinger, 1998). Dichos mecanismos contemplan tanto un aumento de la superficie específica del sistema radical del cultivo como la solubilización de formas de fósforo que no se encuentran disponibles, mediante la excreción de ácidos orgánicos de bajo peso molecular como el oxálico y cítrico (Richardson, 2001). Según este autor tales formas son tanto orgánicas como inorgánicas (fosfatos ligados al calcio, por ejemplo)

En síntesis, la respuesta positiva a la aplicación de tecnologías biológicas que incrementan la eficiencia de utilización de fósforo, como la inoculación con P. bilaii, requiere de la correcta interpretación de la disponibilidad del nutriente en el suelo. En una amplia variación de condiciones ambientales y edáficas como sucede en la región pampeana y mesopotámica argentina, no es posible cuantificar la disponibilidad de fósforo únicamente con la determinación de los tenores de P-extractable mediante el método Bray \& Kurtz $N^{\circ} 1$, sino que se requiere de otros indicadores. Así, los índices k de Langmuir, MBC y DCB caracterizan adecuadamente la disponibilidad del nutriente. De allí que, para una amplia variabilidad de condiciones ambientales y edáficas, la respuesta de los cultivos se asocia positivamente con los sitios de mayor k, mayor MBC y negativamente con el F-Index, razón por la cual se concluye que los efectos positivos de la inoculación con $P$. bilaii están relacionados con condiciones edáficas de baja disponibilidad de fósforo.

Teniendo en cuenta que la interacción P-matriz de suelo afecta la disponibilidad del nutriente, limitando la absorción por parte del cultivo, es necesario promover el desarrollo de estrategias que permitan una mayor absorción del fósforo, ya sea el nativo o el aplicado. En este sentido, la inoculación de las semillas con microorganismos promotores plantea un fructífero campo para lograr avances al respecto.

\section{BIBLIOGRAFÍA}

Asea, P. E. A.; R. M. N. Kucey and J. W. B. Stewart, 1988. Inorganic phosphate solubilization by two Penicillium species in solution culture and soil. Soil Biol. Biochem. 20:59-464.

Axt, J.R and M.R. Walbridge, 1999. Phosphate removal Capacity of palustrine Forested Wetlands and Adjancent Uolands in Virginia. Soil Sci. Soc. Am. J. 63: 10191031.

Bache, B.W. and E.G. Williams, 1971. A phosphate sorption index for soils. J. Soil Sci. 22(3): 289-301.

Beckett, P.H.T. and R.E. White, 1964. Studies on the phosphate potential of soils. III. The pool of labile inorganic phosphate. Plant Soil 21: 253-282.

Börling, K.E.; E. Otabbong and E. Barberis, 2001. Phosphorus sorption in relation to soil properties in some cultivated Swedish soil. Nutr. Cycling Agroecosyst. 59: 39-46.

Chambers, J. W., 1992. Influence of a commercial fungal inoculant (PB-50) on plant nutrient availability and crop growth. M.Sc. Thesis, University of Manitoba, Winnipeg, MB. 306 pp. 
Cunningham, J. E. and C. Kuiack, 1992. Production of citric and oxalic acids and solubilization of calcium phosphate by Penicillium bilaii. Appl. Environ. Microbiol. 58:1451-1458.

Di Rienzo J.A.; F.Casanoves, M.G.Balzarini, L.Gonzalez, M.Tablada y C.W. Robledo, 2011. InfoStat versión 2011. Grupo InfoStat, FCA, Universidad Nacional de Córdoba, Argentina.

Downey, J. and C.H. van Kessel, 1990. Dual inoculation of Pisum sativum with Rhizobium leguminosarum and Penicillium bilaii. Biol. Fertil. Soils 10:194-196.

Gleddie, S. C., 1992. Response of pea to inoculation with the phosphate-solubilizing fungus Penicillium bilaii. M.Sc. thesis, University of Saskatchewan, Saskatoon, SK. 328 pp.

Gleddie, S. C., 1993. Response of pea and lentil to inoculation with the phosphate-solubilizing fungus Penicillium bilaii (Provide). Proc. Soils and Crops Workshop, Saskatoon, SK. pp. 47-52.

Gulden, R. H. and J. K. Vessey, 2000. Penicillium bilaii inoculation increases root-hair production in field pea. Can. J. Plant Sci. 80:801-804.

Hansen, N.C.; T.C. Daniel, A.N. Sharplay and J.L. Lemunyon, 2002. The fate and transport of phosphorus in agricultural systems. J. Soil Water Conserv. 57:408-417.

Heisinger, K. G., 1998. Effect of Penicillium bilaii on root morphology and architecture of pea (Pisum sativum L.). M.Sc. Thesis, University of Manitoba, Winnipeg, MB. 354 pp.

Indiati R.; E. Coppola and A. Buondonno, 1999. Changes of Soil Phosphorus Availability in Italian Alfisols as Estimated by short-Term Soil-Phosphorus equilibration procedures using Olsen, Mehlich 3, and paper strip methods. Commun. Soil Sci. Plant Anal. 30(7-8):983997.

Indiati, R. and A. N. Sharpley, 1995. Soil Phosphate Sorption and Simulated Runnoff Parameters as Affected by Fertilizer Addition and Soil Properties. Commun. Soil Sci. Plant Anal. 26(15-16):2319-2331.

Indiati, R.; C. Izza, A. Figliolia, B. Felici, E. Coppola and A. Buondonno, 1995. A Phosphorus Availability Index (F) for Optimizing a Soil Phosphate Requirement Rating. Commun. Soil Sci. Plant Anal. 26(15-16):2667-2682.

Jensen, H.E., 1971. Phosphate solubility in Danish soils, equilibrated with solutions differing phosphate concentrations. J. Soil Sci. 22(2):261-266.

Keyes, D.O., 1990. Penicillium bilaii: interactions with barley or canola, growth in rhizosphere soil, and overwinter survival. M.Sc. Thesis, University of Alberta, Ed- monton, AB. $188 \mathrm{pp}$

Kucey, R. M. N., 1983. Phosphate-solubilizing bacteria and fungi in various cultivated and virgin Alberta soils. Can. J. Soil Sci. 63:671-678.

Kucey, R. M. N., 1988. Effect of Penicillium bilaii on the solubility and uptake of $\mathrm{P}$ and micronutrients from soil by wheat. Can. J. Soil Sci. 68:261-270.

Kuo, S., 1996. Phosphorus. In: Sparks D.L. (Ed.): Methods of Soil Analysis. Part 3. ASA, SSSA, Madison WI, pp. 869-919.

McDowell, R.W. and Condrom, 2004. Phosphorus loss New Zealand grassland soils. New Zealand. J. Agric. Res. 47:137-145.

Nelson D.W. and L.E. Sommers, 1996. Total carbon, organic carbon, and organic matter. In: Sparks D.L. (Ed.): Methods of Soil Analysis. Part 3. ASA, SSSA, Madison WI, pp. 961-1010.

Reyes I.; L. Bernier and H. Antoun, 2002. Rock phosphate solubilization and colonization of maize rhizosphere by wild and genetically modified strains of Penicillium rugulosum. Microb. Ecol. 44:39-48.

Richardson A. E., 2001. Prospects for using soil microorganisms to improve the acquisition of phosphorus by plants. Aust. J. Plant Physiol. 28:897-906.

Savard M.E.; J.D. Miller, L.A. Blais, K.A. Seifert and R.A. Samson, 1994. Secondary metabolites of Penicilium bilaii strain PB-50. Mycopathologia. Kluwer Academic Pub. 127:19-27.

Silva Rossi, M.M., 2012a. Adsorción y desorción de fósforo en distintas condiciones de suelo y manejo. Editorial Académica Española. LAP LAMBERT Academic Publishing GmbH \& Co KG. Germany. 141 pp.

Silva Rossi, M.M., 2012b. Disponibilidad y eficiencia de absorción de fósforo en trigo, de fertilizantes fosfatados en distintas mezclas con urea. Editorial Académica Española. LAP LAMBERT Academic Publishing GmbH \& Co KG. Germany. 257 pp.

Soil Survey Staff, 2010. Keys to Soil Taxonomy, 11th Ed. USDA-Natural Resources Conservation Service, Washington, DC. 374 pp.

Sparks D., 2003. Environmental Soil Chemistry. $2^{\text {nd }}$ Ed. Ch. 5: Sorption phenomena in soil. Academic Press, San Diego, USA, pp. 133-185.

Vessey, J.K. and K.G. Heisinger, 2001. Effect of Penicillium bilaii inoculation and phosphorus fertilization on root and shoot parameters of field-grown pea. Can. J. Plant Sci. 31:361-366. 